\title{
Percepçáo de profissionais da área de saúde mental sobre o acolhimento ao usuário de substância psicoativa em CAPSad ${ }^{1}$
}

\author{
Daiane Bernardoni Salles ${ }^{a}$, Meire Luci da Silva ${ }^{b}$ \\ ${ }^{a}$ Associação Paulista para o Desenvolvimento da Medicina, São Paulo, SP, Brasil. \\ ${ }^{\text {b} D e p a r t a m e n t o ~ d e ~ F i s i o t e r a p i a ~ e ~ T e r a p i a ~ O c u p a c i o n a l, ~ U n i v e r s i d a d e ~ E s t a d u a l ~ P a u l i s t a ~-~ U N E S P, ~ M a r i ́ l i a, ~ S P, ~ B r a s i l . ~}$
}

\begin{abstract}
Resumo: Introdução: A adesão ao tratamento da dependência química ainda consiste em um grande desafio não só aos usuários, mas também aos profissionais da saúde. Atualmente, as políticas públicas apontam, como ferramenta auxiliar, o desenvolvimento de um modelo de tratamento humanizado, que preconiza a prática do acolhimento. Objetivo: Investigar a percepção dos profissionais de saúde mental sobre o acolhimento oferecido ao usuário de álcool e outras drogas em Centro de Atenção Psicossocial para usuários de álcool e outras drogas (CAPSad). Método: Trata-se de um estudo do tipo exploratório descritivo e qualitativo, realizado em CAPSad do interior paulista. Participaram do estudo, seis profissionais. Para coleta de dados, foi utilizado questionário semiestruturado com 27 perguntas de autopreenchimento, sendo 15 perguntas fechadas, analisadas através de estatística descritiva, e 12 abertas, analisadas pelo método de análise de conteúdo. Resultados: Participaram do estudo, seis profissionais com tempo médio de atuação de 14,3 anos e, destes, nenhum possui capacitação em relação à prática do acolhimento. Neste estudo, cinco responderam realizar acolhimento com presença de familiar, quatro sem a presença de familiar e um prefere deixar a critério do usuário (o mesmo participante poderia assinalar mais de uma resposta). Os resultados demonstram ambiguidade da concepção de acolhimento, já que todos relataram que acolher restringe a recepção do usuário, a escuta qualificada, a orientação e a realização de encaminhamentos necessários. Conclusão: Evidenciou-se necessidade de criação de espaços formais para troca de saberes, discussão e encaminhamentos dos casos, bem como necessidade de incentivo à capacitação profissional, promovendo a identidade do acolhimento no serviço e favorecendo a adesão do usuário ao tratamento.
\end{abstract}

Palavras-chave: Transtornos Relacionados ao Uso de Substâncias, Acolhimento, Serviços de Saúde Mental.

\section{Mental health professional perception of the embracement towards psychoactive substance user in CAPSad}

\begin{abstract}
Introduction: Adherence to chemical dependency treatment is still a great challenge for both, users and health care professionals. Currently, public healthcare policy is a tool to assist in the development of a humanized care model, which advocates for the practice of user inclusion. Objective: Investigate the perception of professionals who work in the mental health field, to understand the inclusion offered to users of psychoactive substances in Psychosocial Care Centers for alcohol and drug users (CAPSad). Method: A descriptive and exploratory study conducted at the CAPSad in São Paulo. Active professionals in the mental health field working at the CAPSad participated in the present study. For data collection a semi-structured questionnaire was used with 27 self-report questions, 15 closed questions, analyzed through statistics and 12 open questions, with speech analysis. Results: The questionnaires of six professionals with a mean of 14.3 years working at the CAPSad, revealed that they had no prior training about inclusion. Five participants responded that they carried out inclusion in the presence of the family, four responded
\end{abstract}

Autor para correspondência: Meire Luci da Silva, Departamento de Fisioterapia e Terapia Ocupacional, Universidade Estadual Paulista, Av. Hygino Muzzi Filho, 737, Mirante, CEP 17525-000, Marília, SP, Brasil, e-mail: meire@marilia.unesp.br 
without the presence of family and just one responded according to user choice (each participant could choose more than one option). The results show ambiguity regarding the concept of user inclusion, as all reported that inclusion hampers user reception, qualified listening, guidance and making necessary referrals. Conclusion: The need to create formal spaces for knowledge exchange, case discussion, and encourage professional training, promoting the identity of the service and improving user adherence to treatment was highlighted.

Keywords: Substance-Related Disorders, User Inclusion, Mental Health Service.

\section{Introdução}

Atualmente, a dependência química e o uso abusivo de substâncias psicoativas constituem-se como importante problema de saúde pública, justiça e social.

Para a Organização Mundial de Saúde (ORGANIZAÇÃO..., 2008), a dependência química é um conjunto de fenômenos fisiológicos, comportamentais e cognitivos que pode se desenvolver depois de repetido uso de substâncias psicoativas. Recentes pesquisas de Carvalho et al. (2011) e Silva, Guimarães e Salles (2014) mostram que os principais motivos que levam ao uso da substância psicoativa são: prazer, ansiedade, inserção social, tensão e evitação do desprazer da sintomatologia pela abstinência.

Com a Reforma Psiquiátrica, a Lei no 10.216 de 6 de abril de 2001 (BRASIL, 2001) garantiu aos usuários de serviços de saúde mental, incluindo os que sofrem por transtornos decorrentes do consumo de álcool e outras drogas, a universalidade de acesso e o direito à assistência, bem como à sua integralidade, valorizando a descentralização do modelo de atendimento. Esta lei determina que os serviços se pautem pelo convívio social dos usuários, atentando-se às desigualdades existentes, cabendo, a estes serviços, atender às necessidades de cada população.

Segundo o Ministério da Saúde (BRASIL, 2003), em sua política para a atenção integral aos usuários de álcool e outras drogas, a assistência a estes usuários deve englobar os três níveis de atenção, tendo como prioridade $\mathrm{o}$ atendimento extra-hospitalar; neste caso, nos Centro de Atençáo Psicossocial para Álcool e Drogas (CAPSad). Ainda, para o Ministério da Saúde, são objetivos de um CAPSad: i) oferecer atendimento à população, respeitando uma área de abrangência definida, oferecendo atividades terapêuticas e preventivas à comunidade, buscando prestar atendimento diário aos usuários dos serviços, dentro da lógica de redução de danos; ii) gerenciar os casos, oferecendo cuidados personalizados; iii) oferecer atendimento nas modalidades intensiva, semi-intensiva e não intensiva, garantindo que os usuários de álcool e outras drogas recebam atenção e acolhimento; iv) oferecer condições para o repouso e a desintoxicação ambulatorial de usuários que necessitem de tais cuidados; v) oferecer cuidados aos familiares dos usuários dos serviços; vi) promover, mediante diversas ações (que envolvam trabalho, cultura, lazer, esclarecimento e educação da população), a reinserção social dos usuários, utilizando para tanto recursos intersetoriais, ou seja, de setores, como educação, esporte, cultura e lazer, montando estratégias conjuntas para o enfrentamento dos problemas; vii) trabalhar, junto a usuários e familiares, os fatores de proteção para o uso e a dependência de substâncias psicoativas, buscando, ao mesmo tempo, minimizar a influência dos fatores de risco para tal consumo; viii) trabalhar a diminuiçáo do estigma e do preconceito relativos ao uso de substâncias psicoativas, mediante atividades de cunho preventivo/educativo.

O Ministério da Saúde propóe a humanização como eixo norteador dos atendimentos através do programa Humaniza SUS e, nesta perspectiva, o acolhimento passa a ser ponto importante e central das discussóes para o desenvolvimento do atendimento humanizado. Carvalho et al. (2008) discorrem que acolhimento significa a humanização do atendimento, envolvendo os processos de trabalho, os quais agregam a relação entre trabalhadores e serviços de saúde com seus usuários. $\mathrm{O}$ acolhimento possibilita e favorece o acesso dos usuários, assegurando-lhes a escuta de suas necessidades de saúde, de forma qualificada, permitindo à equipe a possibilidade $\mathrm{da}$ corresponsabilização do usuário em seu tratamento. Essa forma de atendimento propicia uma nova "porta de entrada", que deve acolher o usuário com qualidade, oferecendo e solucionando as demandas inerentes a cada setor, e encaminhando para outros serviços, quando necessário, garantindo assim o fluxo da rede de atendimento ao usuário.

Segundo Miller e Rollnick (2001), os usuários de substâncias psicoativas são marcados por sentimentos ambivalentes ao buscar ajuda; assim, eles tornam-se mais sensíveis à forma como são acolhidos no serviço. A partir deste pressuposto, acredita-se que a compreensão do profissional atuante na área de saúde mental sobre o entendimento do acolhimento 
ao usuário de álcool e outras drogas pode contribuir para a organização do serviço, o fortalecimento da rede de atenção a este usuário e também para a educação permanente destes profissionais, propiciando, assim, cuidados específicos e individuais ao usuário, e promovendo o aumento de sua vinculaçáo e adesão ao serviço e ao tratamento.

Como forma de possibilitar a identificação das necessidades de formaçáo e desenvolvimento de profissionais em saúde, e de fortificar estratégias de qualificação em atenção e gestão em saúde, foi criada pelo Ministério da Saúde a Política Nacional de Educação Permanente em Saúde (EPS), a partir da Portaria no 198, de fevereiro de 2004 (BRASIL, 2004). Assim, como citam Carotta, Kawamura e Salazar (2009), discussóes à base de acolhimento e humanização tornam-se parte integrante da gestão em saúde, como meta prioritária do Sistema Único de Saúde (SUS).

O objetivo do estudo foi investigar, a partir da percepçáo dos profissionais de saúde mental, o entendimento sobre o acolhimento oferecido ao usuário de álcool e outras substâncias psicoativas em CAPSad.

\section{Método}

Trata-se de um estudo do tipo exploratório descritivo e qualitativo, realizado em um CAPSad de uma cidade do interior paulista. Segundo informaçôes do Ministério da Saúde do ano de 2012 (BRASIL, 2012), existiam 69 CAPSad no Estado de São Paulo, porém Silva et al. (2015) referem que, em 2015, ano no qual esta pesquisa também foi desenvolvida, existiam somente 65 CAPSad em funcionamento em todo o Estado. E ainda, segundo essas autoras, a composição quantitativa da equipe técnica dos CAPSad do Estado de Sáo Paulo variou quantitativamente, sendo a composição da menor equipe técnica de cinco profissionais e da maior, com 23 profissionais.

Ressalta-se que o serviço estudado é referência e único no tratamento da dependência química na região, e está vinculado a uma faculdade de medicina; não obstante, é composto por uma equipe técnica mínima. Participaram da pesquisa, seis profissionais que realizam acolhimento na Unidade, dentre eles: um psicólogo, dois auxiliares de enfermagem, uma enfermeira, uma assistente social e um médico. Dentre os critérios de exclusão, destacam-se a não realização de acolhimento ou a não aceitaçáo de participar do estudo.
O ingresso neste serviço acontece por meio de demanda espontânea ou por encaminhamento via Unidades Básicas de Saúde, Unidades de Saúde da Família ou hospitais, podendo ainda o encaminhamento ser por ordem judicial.

A pesquisa foi aceita pelo Comitê de Ética em Pesquisa da Faculdade Medicina de Marília, sob protocolo 916.902. Os participantes receberam todas as informaçôes e orientaçóes sobre sua participação na pesquisa e assinaram o Termo de Consentimento Livre e Esclarecido

Para a coleta de dados, foi elaborado e aplicado pela equipe de pesquisa um questionário com 27 questôes de autopreenchimento, sendo 15 perguntas fechadas e 12 perguntas abertas, permitindo ao profissional especificar sua percepção sobre acolhimento ao usuário do serviço de álcool e drogas. O conteúdo das questóes era referente à escolha do profissional em relação à área de serviço, ao entendimento sobre acolhimento, às possibilidades de discussóes do tema eà autoavaliaçáo sobre sua atuaçâo e realidade profissional.

O instrumento foi respondido de forma individual, conforme orientação do pesquisador. As informações sobre o projeto foram dadas de maneira a não influenciar o participante em suas respostas. A coleta de dados foi realizada entre os períodos de dezembro de 2014 e janeiro de 2015.

Os resultados das perguntas fechadas foram analisados por meio de estatística simples descritiva, para melhor exposição dos dados. A análise dos resultados das perguntas abertas foi realizada conforme proposta de Bardin (1977), por meio da análise de conteúdo temático. Os temas foram selecionados pela pesquisadora para melhor exposição dos dados, conforme o objetivo proposto pela pesquisa.

\section{Resultados}

Atualmente, trabalham no CAPSad pesquisado, nove profissionais da área de saúde, dentre eles: três médicos psiquiatras, uma assistente social, um psicólogo, dois enfermeiros e dois auxiliares de enfermagem, sendo que, destes, seis profissionais aceitaram participar da pesquisa. Os que aceitaram foram: um médico, um psicólogo, uma assistente social, uma enfermeira e dois auxiliares de enfermagem. A média de idade dos participantes foi de 45,8 anos com desvio padrão de \pm 7 anos, com tempo de formados de 18,3 $\pm 8,5$ anos, sendo $50 \%$ (3) do gênero feminino e $50 \%$ (3) do gênero masculino.

Os participantes pesquisados apresentaram tempo de atuação com média de $14,3 \pm 6,7$ anos. Ao serem 
questionados sobre o trabalho com dependência química ter sido sua área de escolha profissional, $33 \%$ (2) tiveram resposta afirmativa e 67\% (4) referiram não ter sido sua primeira escolha. Em relação ao primeiro contato com usuário que abusa de substâncias psicoativas, $50 \%$ (3) relataram ter sido no ambiente familiar, enquanto $33 \%$ (2) responderam ter tido o primeiro contato no ambiente profissional e $17 \%$ (1) com amigos. Quanto à realização de especializaçôes na área de saúde mental, 50\% (3) responderam afirmativamente, sendo referidos: um aprimoramento, duas especializaçóes e um mestrado. Este fato não ocorreu em relação às capacitaçôes, em que somente dois profissionais $(33 \%)$ relataram ter algum tipo de capacitação na área, sendo um deles também com especialização. Dentre as capacitaçóes específicas sobre o tema acolhimento, $100 \%$ (6) disseram nunca terem realizado.

Com relaçáo à fonte de recurso para o financiamento das especializaçóes e capacitaçôes, $50 \%$ (2) referiram ter realizado com recurso próprio, $25 \%$ (1) com recurso institucional e $50 \%$ (2) gratuito. É importante ressaltar que, neste item, foram citadas capacitaçóes realizadas à distância. Dos quatro profissionais que possuem algum tipo de especialização ou capacitação, 50\% (2) deles responderam ter realizado tal aprimoramento após o ingresso no serviço e $50 \%$ (2) referiram ter realizado em ambos os momentos, antes e após o ingresso ao serviço.

Dentre os participantes, $33 \%$ (2) são técnicos de referência de 25 usuários cada, $17 \%$ (1) de 15 usuários, sendo tais profissionais com formação de nível superior; os demais 50\% (3) não são técnicos de referência de nenhum usuário.

Já em relação à temática "entendimento sobre acolhimento", todos os participantes relataram que entendem por acolher, receber o usuário no serviço, ouvir suas demandas de forma qualificada, orientar e fazer os encaminhamentos necessários, como destacado pela fala:

Acolher é ter uma escuta qualificada para as queixas do individuo, identificar as necessidades com o usuário e dar uma resposta às queixas e necessidades, envolvendo-o na elaboração do cuidado (P1).

Referiram, ainda, o acolhimento como sendo o início do acompanhamento deste paciente no tratamento, o que fica bem evidenciado nesta fala:

\section{Acolhimento é o início do acompanhamento} (P6).

Quanto ao tipo de acolhimento realizado, $100 \%$ (6) dos participantes relataram que fazem o acolhimento individual ao usuário e, dentre estes participantes, 67\% (4) disseram também realizar grupos de acolhimento. Em outro item, em relação a ter companhia ou não durante o acolhimento, $83 \%$ (5) realizam com a presença de familiar, $67 \%$ (4) sem a presença de familiar e $17 \%$ (1) refere deixar a critério do usuário.

Os profissionais responderam que não estabelecem um número de acolhimentos a cada usuário, sendo este número flexível quanto às suas necessidades.

\section{Depende da necessidade de cada pessoa (P3).}

Quando questionados sobre a via de atendimento dos acolhimentos realizados, $100 \%$ (6) responderam ser via demanda espontânea e 17\% (1) disseram realizar acolhimento via agendamento prévio.

No quesito "sistematização do acolhimento", apenas $17 \%$ (1) relataram usar algum tipo de protocolo para realização deste, sendo tal documento elaborado por outros colegas do serviço e que engloba aspectos como tipo de substância consumida, período de abstinência, tratamentos anteriores, entre outros.

Em relação às discussões em equipe acerca do acolhimento realizado, $83 \%$ (5) responderam que sempre fazem discussões e 17\% (1) responderam que nem sempre a discussão é realizada. Quanto aos profissionais com os quais discutem, $100 \%$ (6) relataram fazer a discussáo com equipe multidisciplinar, podendo, em alguns casos, ser exclusivamente com a equipe médica.

Os assuntos abordados nas discussões sobre o acolhimento, segundo os participantes, são, principalmente, referentes à coleta de dados realizada durante o acolhimento, a fim de possibilitar o encaminhamento e/ou modalidade de tratamento oferecido ao usuário, conforme evidenciado em:

Motivação, tempo de abstinência, coleta de dados, proposta terapêutica elou conduta (P4).

Já quando questionados se existem períodos e/ou reuniōes formais para as discussóes dos acolhimentos, $83 \%$ (5) responderam negativamente e $17 \%$ (1) afirmativamente, sendo referenciada a reunião de equipe semanal como o momento para tais discussōes.

$\mathrm{Na}$ temática referente à "função do acolhimento ao usuário", todos os participantes evidenciaram o acolhimento como forma de orientaçáo quanto ao tratamento. Dentre estes, apenas 33\% (2) correlacionaram o acolhimento como uma forma de estimular a adesão ao tratamento, sendo o início do vínculo serviço/usuário, explicitado em:

Ouvir o usuário, orientar sobre o tratamento, estimular a adesão (P2). 
Acolher o individuo, ter escuta ampliada sobre suas dificuldades, fazer vinculo e oferecer proposta terapêutica (P4).

Na categoria relacionada à realização de possíveis alterações em seu acolhimento, 67\% (4) responderam que sim, podendo tal disposição ser evidenciada pela fala:

\section{Sempre é possivel melhorar (P5).}

A última temática selecionada diz respeito ao "entendimento sobre acolhimento ideal", em cuja análise das respostas, todos os participantes apontaram para a preocupação de um atendimento ágil e instantâneo no momento da procura, prezando a escuta qualificada, a realização de orientações necessárias e os possíveis encaminhamentos. Destacaram também a necessidade de uma rede de suporte bem estruturada, explicitada em:

$O$ acolbimento ideal deveria ter equipe multiprofissional designada para receber, ouvir as pessoas que buscam o serviço, ter mais profissionais na equipe, ter um trabalho de acolhida não só com a visão de inserção no tratamento, mas também em orientação (P3).

Se houvesse rede de suporte estruturada nas politicas de saúde (P4).

O tempo é curto em função da demanda, condiçóes físicas do ambiente... bem como realiza-lo em equipe (P6).

\section{Discussão}

Os resultados apontaram que a escolha em trabalhar com saúde mental, muitas vezes, está associada à oferta de emprego e não necessariamente como a primeira escolha do trabalhador. Este fato pode resultar em serviços compostos por um quadro de profissionais que, muitas vezes, não se identifica com o ambiente, com o tipo de serviço prestado e também com o usuário atendido. Neste estudo, os participantes relataram que trabalhar com dependência química não foi uma escolha pessoal e profissional, o que é corroborado por Tavares (2006), em pesquisa realizada com profissionais em serviços especializados em saúde mental, em que a oferta de emprego nem sempre permite a escolha pela área desejada.

Sabe-se que o consumo de substâncias tem se intensificado e agravado a cada ano, de forma concomitante ao aumento de produçấo e desenvolvimento de novas substâncias (UNITED..., 2013), sendo possível o contato com um usuário de substância psicoativa mostrar-se cada vez mais rotineiro e frequente. Quando questionados sobre o primeiro contato com usuários que abusam de substâncias psicoativas, parte dos participantes respondeu que o primeiro contato se deu no ambiente familiar; já Lopes et al. (2009) apontam que o primeiro contato, quando pesquisados alunos de enfermagem, se deu no ambiente profissional, o que pode estar relacionado com o pouco entendimento, quanto ao abuso de substâncias na sociedade em geral, sobre o assunto.

As especializaçôes e capacitaçôes são formas de aproximar o profissional de novas técnicas e conhecimentos acerca de sua prática profissional, o que facilita, proporciona suporte e dá maior autonomia no momento de lidar com situaçôes até então desconhecidas. Para Silva et al. (2007), os cursos e capacitaçóes podem ocorrer de forma desarticulada com as reais necessidades do trabalhador e do usuário do serviço, sendo importante o desenvolvimento de abordagens que contemplem o contexto institucional, auxiliando na promoção da articulação de diálogos e do estabelecimento de relaçóes entre os atores do tratamento (profissionais/usuários).

Nesta pesquisa, metade dos participantes tem alguma especialização, cursos exclusivos para profissionais de nível superior na ou da área de dependência química específica ou de saúde mental. Tal fato contribui de forma favorável para o melhor planejamento do serviço, já que, dos profissionais de ensino superior participantes, apenas um relatou não ter qualquer especialização.

No quesito "capacitaçóes", alguns responderam ter realizado alguma, sendo que um deles também realizou especialização; referiram, ainda, que o financiamento para a realização destas foi a partir de recursos próprios. Um fator que pode também colaborar para a dificuldade na realização das capacitaçóes e especializaçóes pode estar relacionado à falta de incentivo por parte da própria instituição, que, muitas vezes, náo permite o afastamento para realização de cursos, questão esta também apontada por Vargas e Duarte (2001).

Quanto à necessidade de capacitaçôes e especializaçôes de profissionais da saúde mental, estas sempre estiveram contempladas e reafirmadas nos documentos do Ministério da Saúde, englobando novas técnicas e formação desses profissionais, a fim de lidar com o novo paradigma de saúde, como cita Silva, Oliveira e Postigo (2014). Além da necessidade já citada, Gallassi e Santos (2013) trazem as dificuldades encontradas quando abordado o assunto da dependência química, reiterando as capacitaçóes muito espaçadas e muitas vezes distantes da necessidade do profissional, uma formação acadêmica com carga horária escassa sobre 
o assunto e a questão ainda muita arraigada de um conceito moral, de forma histórica.

Mângia et al. (2006) discorrem que a referência técnica promove um processo de trabalho em que um profissional é designado para assumir de forma diferenciada as negociaçóes com o usuário sobre necessidades em seu tratamento. O técnico de referência, na maioria das vezes, é o profissional com maior vínculo com o usuário, o que possibilita a divisão de tarefas entre os profissionais da equipe. Neste estudo, os profissionais referem ser técnicos de referência, sendo, um deles, o médico designado para o caso. Neste sentido, há uma preocupação com o vínculo profissional/usuário que pode não ser o mais próximo, já que nem toda a equipe está disponível para esta tarefa, além de poder gerar uma sobrecarga para os que executam esta função.

Segundo o Ministério da Saúde (BRASIL, 2006), o acolhimento, muito além de seu significado semântico, é uma forma de operar os processos de trabalho em saúde, a fim de proporcionar atendimento a todos aqueles que buscam o serviço, de forma qualificada. O acolhimento é, então, a porta de entrada do serviço e sua qualificação pode estar diretamente ligada à adesão do usuário ao tratamento, já que influencia no fluxo de usuários que permanecerão por vontade própria naquele serviço, favorecendo o protagonismo em seu tratamento.

Para Oliveira et al. (2011), o acolhimento tem como função a escuta qualificada às demandas de todo usuário que chega a qualquer serviço de saúde, sendo esperado que o profissional apresente resolutividade frente às queixas do usuário, porém demonstre a necessidade da corresponsabilizaçáo deste em seu tratamento, levando em consideração todo seu contexto sócio-histórico e familiar. Segundo Andrade, Sousa e Quinderé (2013), o acolhimento deve ser livre de julgamentos, respeitando as necessidades, os desejos e as diferenças do usuário, o que é apontado também por Alves e Oliveira (2010), que definem a escuta qualificada como o ouvir o usuário sem julgamentos, quanto ao conteúdo ou mesmo ao nexo neste momento, mas o simples compartilhamento da situação de sofrimento, que o motiva para a busca de tratamento em um serviço de saúde. É necessário estar atento ao que o usuário traz, como sua história, muito antes de estruturar alguma possível intervenção.

Os resultados apontaram para a sensibilidade dos profissionais pesquisados sobre o acolhimento e a importância deste, como o momento crucial na formação de vínculo usuário/serviço. Em contrapartida, apresentaram uma enorme preocupação em coletar dados e oferecer rapidamente uma resposta frente às necessidades do usuário, a partir da elaboração de um projeto terapêutico ou de possíveis encaminhamentos, podendo, em alguns momentos, o acolhimento se assemelhar à triagem propriamente dita, como também observado por Andrade, Sousa e Quinderé (2013).

Acredita-se que essa indiferenciação, presente em alguns momentos, entre acolhimento e triagem deva ser motivo de atenção por parte da equipe, considerando que este paciente possa estar em um momento de pré-contemplação ou contemplação para o tratamento, para o qual sua motivação pode se apresentar flutuante. O acolhimento também foi considerado de grande valia para a efetivação da vinculaçáo do usuário/serviço e de adesão deste ao tratamento.

Quanto aos tipos de acolhimentos realizados, há consonância com as diretrizes do SUS quanto à função do acolhimento, porém o discurso do acolhimento em grupo, também presente, difere do proposto. Segundo Azambuja et al. (2007), o acolhimento em grupo dever funcionar como um grupo de sala de espera, em que os usuários podem compartilhar formas de pensar em saúde, não excluindo o atendimento de forma individual.

Sabe-se que a dependência química afeta diretamente o contexto familiar. Assim, é de extrema importância a participação da família durante todo o processo do tratamento. A participação da família, quando no papel de apoiadora do tratamento, durante o acolhimento, pode gerar maior confiança no paciente durante a exposiçáo de seus problemas e contribuir para melhor contextualização da situação. Seadi e Oliveira (2009), em pesquisa realizada, encontraram maior adesão do paciente ao tratamento quando familiares também participam ou colaboram diretamente neste processo, corroborando com o encontrado nesta pesquisa, quando permitem a presença do familiar no acolhimento. Sendo o acolhimento uma forma de escuta qualificada, que deve atender a todo usuário que chega ao serviço, definir um número de acolhimentos por usuário vai na contramão do proposto de individualizar o tratamento. Neste estudo, os participantes demonstraram bom entendimento quanto à necessidade de acolher a demanda trazida por cada indivíduo.

Em se tratando da motivação flutuante do usuário de substâncias psicoativas quanto ao desejo de tratamento, acolhê-lo de forma imediata à procura do serviço possibilita uma melhor adesão ao tratamento (CASTRO; PASSOS, 2005), corroborando com o encontrado nesta pesquisa.

Adotar um protocolo para acolhimento pode ser uma maneira de simplificar a escuta e de aproximação 
a uma triagem. Tal fato pode estar ligado, muitas vezes, à falta de disponibilidade de profissionais suficientes para um acolhimento adequado, o que é corroborado por Oliveira et al. (2010), que discutem o reduzido número de profissionais especializados ou os recursos insuficientes para manter uma equipe multidisciplinar disponível apenas para a função de acolher.

Vargas e Duarte (2001) salientam a importância da troca de informaçóes entre os próprios profissionais do serviço como uma fonte de conhecimentos, já que as especializaçôes e capacitaçôes são pouco difundidas nestes ambientes. As discussóes, quando não realizadas em espaços formais, como encontrado nesta pesquisa, não favorecem o fortalecimento das trocas de conhecimento e experiências da equipe, já que só alguns profissionais fazem parte deste momento. Se esse modo disperso é agregado à falta de capacitação específica sobre acolhimento, pode acarretar uma dificuldade em criar vínculo com este usuário, que terá que adaptar-se às formas individuais de cada profissional de lidar com o acolhimento, descaracterizando uma identidade do serviço.

Em relação aos assuntos abordados nas discussôes sobre o acolhimento, ressalta-se a coleta de dados realizada durante o acolhimento como forma auxiliar - e até principal - do encaminhamento do usuário para modalidade de tratamento oferecido. Deve-se tomar cuidado para não confundir acolhimento com a simples coleta de dados, deixando de lado a singularidade de cada indivíduo. Para Rêgo (2009), o acolhimento deve fornecer um diagnóstico situacional de cada usuário, para, em seguida, ser elaborado o plano terapêutico. Talvez, neste primeiro momento, seja difícil traçar a modalidade de tratamento na qual o indivíduo se encaixe, restando pouco espaço para a singularidade e o contexto trazido por cada usuário que procure o serviço.

$\mathrm{O}$ acolhimento é então um grande aliado à adesão ao tratamento, conforme referido por Andrade, Sousa e Quinderé (2013), Solla (2005) e Schmidt e Figueiredo (2009). Com o número de participantes relatando o acolhimento como forma de adesão, demonstra-se uma fragilidade no entendimento da função do acolhimento, segundo as diretrizes do SUS, ficando evidenciada a orientação como principal função do acolhimento para os participantes.

Evidenciou-se também a crítica por parte dos participantes quanto a possíveis melhoras no acolhimento realizado. Quando questionados sobre o "acolhimento ideal", os participantes citaram a necessidade de uma equipe multidisciplinar específica para o acolhimento, favorecendo a escuta no momento em que o usuário busca o serviço, além de melhores condiçóes físicas. O número reduzido de funcionários e a inadequação do ambiente foram itens destacados por Oliveira et al. (2010), que referem que a vulnerabilidade destes itens fragiliza a proposta de repensar os processos de trabalho, lidando com a frustração do profissional em atuar entre a expectativa e a realidade de seu trabalho, limitando inclusive o tempo disponível para cada função.

\section{Conclusão}

O estudo permitiu evidenciar a percepção dos profissionais de saúde mental acerca do acolhimento ao usuário de substâncias psicoativas em um CAPSad.

Através do questionário utilizado, foi possível identificar uma preocupação em fornecer um acolhimento a todo usuário que busca o serviço, porém também apontou a dificuldade em manter as diretrizes do SUS, o que pode ser percebido como resultante do baixo número de capacitaçôes realizadas e do pouco incentivo para tais. Ficou evidente que a concepção de acolhimento ainda está vinculada à necessidade de coleta de dados.

Uma forma de lidar com o número restrito de capacitaçôes seria a implantação de espaços formais de discussão em equipe, favorecendo a troca de saberes e a facilitação da criação de identidade ao acolhimento do serviço, além da implementação de educação permanente aos profissionais atuantes.

A sobrecarga, muitas vezes acarretada pelo exíguo quadro de funcionários, é tema a ser discutido em toda a rede de serviços de saúde, que hoje, em sua maioria, funciona com o quadro mínimo exigido. Dessa forma, desempenhar todas as funçóes de forma qualificada pode trazer enorme sobrecarga e estresse ao profissional, que, além de ter de lidar com suas próprias frustraçóes, deve estar sempre disponível ao sofrimento do usuário, já que um acolhimento insatisfatório poderá dificultar a adesão do usuário ao tratamento.

Mediante os itens destacados e supra discutidos, deve-se tomar cuidado para que os serviços substitutivos náo reproduzam a forma de cuidar dos modelos asilares. Para isso, o investimento em conhecimento e subsídios para o profissional é de extrema importância.

Repensar na forma de estruturação do serviço e contemplar espaços de troca e capacitação é proporcionar um atendimento de qualidade ao usuário e também proporcionar a manutenção do bem-estar profissional, a fim de que este profissional adquira autonomia e manejo para lidar com as 
situaçóes vivenciadas no cotidiano do tratamento da dependência química.

Espera-se, com este estudo, contribuir para uma reorganização dos processos de trabalho, fomentando espaços de troca de saberes, fortalecendo o acolhimento como forma de atendimento pautado na escuta qualificada, priorizando a singularidade de cada indivíduo, sem conceitos pré-estabelecidos, e favorecendo, assim, maior adesão do usuário ao tratamento e, consequentemente, menor evasão do mesmo.

Novas pesquisas podem contribuir para maiores reflexôes acerca do olhar do profissional desta área, permitindo cada vez mais discussóes que contribuam para a qualificaçáo e o fortalecimento da rede de atençáo ao usuário de substâncias psicoativas no atendimento prestado.

\section{Referências}

ALVES, M.; OLIVEIRA, R. M. P. Enfermagem psiquiátrica: discursando o ideal e praticando o real. Escola Anna Nery Revista de Enfermagem, Rio de Janeiro, v. 14, n. 1, p. 64-70, 2010.

ANDRADE, A. T.; SOUSA, M. L. T.; QUINDERÉ, P. H. D. Acolhimento no Centro de Atenção Psicossocial para álcool e outras drogas: concepçôes dos trabalhadores de saúde. Pesquisas e Práticas Psicossociais, São João del-Rei, v. 8, n. 2, p. 166-175, 2013.

AZAMBUJA, M. P. R. et al. Relato de experiência: o acolhimento em grupo como uma estratégia para a integralidade. Psico-USF, Itatiba, v. 12, n. 1, p. 121-124, 2007.

BARDIN, L. Análise de conteúdo. Lisboa: Ediçôes 70, 1977.

BRASIL. Lei no 10.216, de 6 de abril de 2001. Dispóe sobre a proteção e os direitos das pessoas portadoras de transtornos mentais e redireciona o modelo assistencial em saúde mental. Diário Oficial [da] República Federativa do Brasil, Poder Executivo, Brasília, DF, 9 abr. 2001.

BRASIL. Ministério da Saúde. Secretaria Executiva. Coordenaçáo Nacional de DST/Aids. A política do Ministério da Saúde para atenção integral a usuários de álcool e outras drogas. Brasília, 2003.

BRASIL. Ministério da Saúde. Portaria no 198 GM, de 13 de fevereiro de 2004. Institui a Política Nacional de Educação Permanente em Saúde como estratégia do Sistema Ứnico de Saúde para a formação e o desenvolvimento de trabalhadores para o setor e dá outras providências. Diário Oficial [da] República Federativa do Brasil, Poder Executivo, Brasília, DF, 13 fev. 2004.

BRASIL. Ministério da Saúde. Secretaria de Atenção à Saúde. Núcleo Técnico da Política Nacional de Humanização. Acolhimento nas práticas de produção de saúde. Brasília, 2006.
BRASIL. Ministério da Saúde. Saúde Mental em Dados 10. Brasília, 2012. Informativo eletrônico de dados sobre a Política Nacional de Saúde Mental, ano VII, n. 10.

CAROTTA, F.; KAWAMURA, D.; SALAZAR, J. Educação Permanente em Saúde: uma estratégia de gestão para pensar, refletir e construir práticas educativas e processos de trabalhos. Saúde e Sociedade, São Paulo, v. 18, p. 48-51, 2009. Suplemento 1.

CARVALHO, C. A. P. et al. Acolhimento aos usuários: uma revisão sistemática do atendimento no Sistema Único de Saúde. Arquivos de Ciências da Saúde, São José do Rio Preto, v. 15, n. 2, p. 93-95, 2008.

CARVALHO, R. M. C. et al. Causas de recaída e de busca por tratamento referidas por dependentes químicos em uma unidade de reabilitação. Columbia Médica, Colombia, v. 42, n. 2, p. 57-62, 2011.

CASTRO, M. M. L. D.; PASSOS, S. R. L. Entrevista motivacional e escalas de motivaçấo para tratamento de dependência de drogas. Archives of Clinical Psychiatry, São Paulo, v. 32, n. 6, p. 330-335, 2005.

GALLASSI, A.; SANTOS, V. O abuso de drogas: desafios e opçôes para a prática do profissional de saúde no Brasil. Brasília Médica, Brasília, v. 50, n. 1, p. 51-57, 2013.

LOPES, G. T. et al. Nursing students' conceptions about the user of drugs. Revista Brasileira de Enfermagem, Brasília, v. 62, n. 4, p. 518-523, 2009.

MÂNGIA, E. F. et al. A construção de projetos terapêuticos. Revista de Terapia Ocupacional da Universidade de São Paulo, São Paulo, v. 7, n. 2, p. 87-98, 2006.

MILLER, W. R.; ROLLNICK, S. Entrevista motivacional: preparando as pessoas para a mudança de comportamentos adictivos. Porto Alegre: Artes Médicas, 2001.

OLIVEIRA, E. et al. Práticas Assistenciais no Centro de Atenção Psicossocial de Álcool, Tabaco, e outras Drogas. Revista de Terapia Ocupacional da Universidade de São Paulo, São Paulo, v. 21, n. 3, p. 247-254, 2010.

OLIVEIRA, L. S. A. et al. Percepçóes de monitores do pet-saúde mental sobre o acolhimento aos indivíduos atendidos no CAPS-AD do Distrito Glória/ Cruzeiro/ Cristal. In: SALĀO DE ENSINO, 7., 2011, Porto Alegre. Anais... Porto Alegre, 2011.

ORGANIZAÇÃO MUNDIAL DE SAÚDE - OMS. Classificação estatística internacional de doenças e problemas relacionados à saúde - CID-10. São Paulo: EDUSP, 2008.

RÊGO, M. Toxicomania: movimento de uma clínica. In: NERY FILHO, A. (Ed.). Toxicomanias: incidências clínicas e sociantropológicas. Salvador: EDUFBA CETAD, 2009. p. 207-220.

SCHMIDT, M. B.; FIGUEIREDO, A. C. Acesso, acolhimento e acompanhamento: três desafios para o cotidiano da clínica em saúde mental. Revista Latinoameri- 
cana de Psicopatologia Fundamental, São Paulo, v. 12, n. 1, p. 130-140, 2009.

SEADI, S. M. S.; OLIVEIRA, M. S. A terapia multifamiliar no tratamento da dependência química: um estudo retrospectivo de seis anos. Psicologia Clínica, Rio de Janeiro, v. 21, n. 2, p. 363-378, 2009.

SILVA, C. R. et al. Mapeamento da atuação do terapeuta ocupacional nos Centros de Atenção Psicossocial Álcool e Drogas (CAPS ad) do interior do estado de Sáo Paulo. Cadernos de Terapia Ocupacional da UFSCar, São Carlos, v. 23, n. 2, p.321-334, 2015.

SILVA, J. A. M. et al. Capacitação dos trabalhadores de saúde na atenção básica: impactos e perspectivas. Revista Eletrônica de Enfermagem, Goiânia, v. 9, n. 2, p. 389401, 2007.

SILVA, M. L.; GUIMARÃES, C. F.; SALLES, D. B. Risk and protective factors to prevent relapses of psychoactive substances users. Revista RENE, Ceará, v. 15, n. 6, p. 1007-1015, 2014.
SILVA, S. P.; OLIVEIRA, A. L.; POSTIGO, Q. Capacitação em saúde mental: entre a realidade e as ofertas do ministério da saúde. Sistema \& Gestão, Rio de Janeiro, v. 9, n. 3, p. 406-416, 2014.

SOLLA, J. J. S. P. Acolhimento no sistema municipal de saúde. Revista Brasileira de Saúde Materno Infantil, Recife, v. 5, n. 4, p. 493-503, 2005.

TAVARES, C. M. M. A educação permanente da equipe de enfermagem para o cuidado nos serviços de saúde mental. Texto \& Contexto - Enfermagem, Florianópolis, v. 15, n. 2, p. 287-295, 2006.

UNITED NATIONS OFFICE ON DRUGS AND CRIME - UNODC. World Drug Report. Austria, 2013.

VARGAS, D.; DUARTE, F. A. B. Enfermeiros dos Centros de Atenção Psicossocial em Álcool e drogas (CAPSAD): a formação e a busca pelo conhecimento específico da área. Texto \& Contexto - Enfermagem, Florianópolis, v. 20, n. 1, p. 119-126, 2001.

\section{Contribuição dos Autores}

Daiane Bernardoni Salles e Meire Luci da Silva participaram integral e igualmente de todas as etapas de elaboração e redação do artigo. Todos os autores aprovaram a versão final do texto.

\section{Notas}

${ }^{1}$ Este trabalho é um recorte de uma pesquisa temática e foi parte integrante do Trabalho de Conclusão de Curso do Programa Multiprofissional em Saúde Mental da Faculdade de Medicina de Marília - FAMEMA, Marília, SP, Brasil. 2015. 